\title{
WELDABILITY OF Ni-BASED SUPERALLOYS
}

\author{
Joel Andersson ${ }^{1,2,3}$ \\ ${ }^{1}$ GKN Aerospace Engine Systems, Trollhättan, SE-461 81, Sweden \\ ${ }^{2}$ Department of Engineering Science, University West, Trollhättan, SE-461 86, Sweden \\ ${ }^{3}$ Department of Materials and Manufacturing Technology, Chalmers University of Technology, \\ Gothenburg, SE-412 96, Sweden
}

Keywords: Weldability; Ni-based, Superalloys; Cracking

\begin{abstract}
This paper reviews the inherent weldability of precipitation hardening Ni-based superalloys commonly used in structural components of aircraft engines. Weldability often refers to alloys resistant to cracking during welding which for superalloys is difficult to comprehend since specific liquation and cracking mechanism may differ in this class of materials. A new procedure of evaluating the weldability as well as susceptibility towards strain age cracking of these alloys is proposed in which standard metallographic examinations are used to understand the cracking mechanisms in parallel with systematic ductility measurements such as Varestraint or Gleeble testing.
\end{abstract}

\section{Introduction}

Superalloys in general and Ni-based superalloys in particular belong to an important group of materials very useful in aerospace applications. The reason for this is the fact that superalloys possess a unique combination of high strength, supreme oxidation/corrosion resistance and adequate processing capabilities [1].

Superalloys can be divided into different groups where the hardening mechanisms often serve as denominators i.e.; solid solution hardening, oxide dispersion hardening (ODS) and precipitation hardening [2]. Here the precipitation hardening alloys, treated in this paper, such as Alloy 718 and Waspaloy emerged in the forties and more or less paved the way for the development of advanced jet engines [2].

Alloy 718 is today the most frequently used superalloy. A reason for this success is a plethora of useful material properties such as high strength and very good oxidation resistance but also the process ability which made it possible to produce parts not only as casting but also as forgings. This shape flexibility has been shown to be important in order to weight optimize hot structural components for aero engines such as the one seen in Figure 1. In a component of this kind, cast shapes are used where the geometry is complex and strength requirements moderate, while forged/wrought parts are used where geometry is less complex but strength requirements are higher [3]. It's also possible to join different alloys for the optimization. From an aerospace standard practice, processes such as gas tungsten arc welding (GTAW) or plasma arc welding (PAW) may be involved on the high energy heat input side of weld processes whereas laser beam welding (LBW) and electron beam welding (EBW) could be involved on the low energy heat input side. There are many aspects to consider when deciding which process to choose. A few aspects are; the material thickness, impact on component distortion as a consequence of the heat input from the specific welding process, element dilution, ability to automate the process 
and so on. Regardless, the methods used in the actual fabrication, a fabrication of the type as seen in Figure 1 below may contain meters of "tricky" welds. It's of utmost importance that the weld quality is on track to succeed in producing hundreds of these structures.

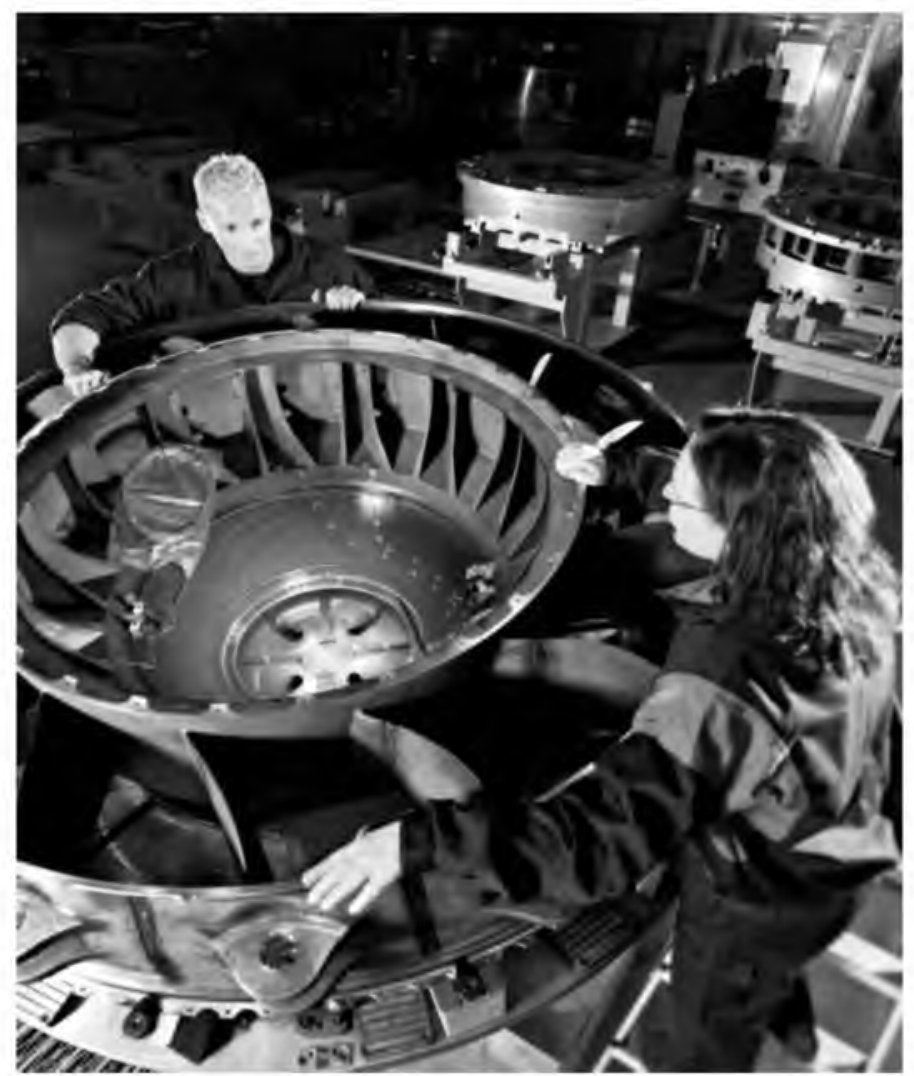

Figure 1. A hot structural component with a large number of cast and wrought Alloy 718 parts joined by welding.

\section{Background}

From a historical perspective, fabrication of structural components in aero engines were actually the starting point to produce components similar to the one seen in the Figure above since the investment casting process was not presently available to comply with the requirements needed to produce acceptable quality. As the ability to cast in vacuum came around, things were turning around, and structural components were instead produced as single piece castings instead of being fabricated by joining small parts together by welding. However, the price of a single piece casting as well as the ability to tailor these components through fabrication has in turn switched back to fabrication.

As for alloy development, both Alloy 718 as well as ATI 718 Plus ${ }^{\circledR}$ were first available in the wrought form then later also in cast versions (ongoing for ATI 718Plus ${ }^{\mathbb{B}}$ ). Waspaloy was developed a few years ahead of Alloy 718 and gave a nice boost to engine performance. However, it suffers from poor weldability, to be more precise, a high susceptibility to strain age cracking (SAC). The industry therefore demanded an alloy that did not possess this high risk of $\mathrm{SAC}$ which became a major driver for the development of Alloy 718. Alloy 718 is more or less immune to SAC. The low susceptibility towards SAC does not come alone. It comes with its biggest drawback, that is, from a performance point of view. Its main strengthening phase, $\gamma$ ' $\left(\mathrm{Ni}_{3} \mathrm{Nb}\right.$ ), is not stable above $\sim 650{ }^{\circ} \mathrm{C}$ and as a consequence the alloy will not maintain its 
strength above this temperature. Above $\sim 650^{\circ} \mathrm{C}$ another precipitation hardening phase named $\gamma^{\prime}$ $\left(\mathrm{Ni}_{3} \mathrm{Al}, \mathrm{Ti}\right)$ is stable and thus useful. The $\gamma^{\prime}$ phase is commonly found in superalloys containing $\mathrm{Al}$ and/or $\mathrm{Ti}$ and is the main hardening constituent in alloys as Waspaloy, ATI 718Plus ${ }^{\mathbb{B}}$ and Haynes ${ }^{\circledR} 282^{\circledR}$. The typical chemical composition (wt. \%) of these four precipitation hardening superalloys are shown in table 1 .

Table 1. Typical chemical composition in wt. \% of Alloy 718 [4], Waspaloy [5], ATI718Plus ${ }^{\circledR}$ [6] and Haynes ${ }^{\mathbb{R}} 282^{\mathbb{R}}[7]$.

\begin{tabular}{|c|c|c|c|c|}
\hline Element & Alloy 718 & Waspaloy & ATI 718Plus ${ }^{R}$ & Haynes $^{(R)}$ 282 $^{(\mathrm{R})}$ \\
\hline $\mathbf{N i}$ & Bal. & Bal. & Bal. & Bal. \\
\hline $\mathrm{Cr}$ & 18.4 & 19.2 & 18.0 & 19.6 \\
\hline $\mathbf{F e}$ & 17.9 & 1.0 & 9.4 & 0.4 \\
\hline Co & - & 13.3 & 9.2 & 10.4 \\
\hline Mo & 3.1 & 4.0 & 2.7 & 8.6 \\
\hline Al & 0.6 & 1.3 & 1.5 & 1.4 \\
\hline $\mathbf{T i}$ & 0.9 & 3.1 & 0.8 & 2.2 \\
\hline $\mathbf{N b}$ & 5.0 & - & 5.5 & - \\
\hline $\mathrm{C}$ & 0.03 & 0.03 & 0.02 & 0.07 \\
\hline $\mathbf{P}$ & - & 0.002 & 0.005 & 0.002 \\
\hline B & 0.002 & 0.005 & 0.005 & 0.004 \\
\hline $\mathbf{C u}$ & - & 0.01 & 0.01 & - \\
\hline Mn & - & 0.02 & 0.03 & 0.08 \\
\hline $\mathbf{S}$ & - & 0.0004 & 0.0003 & 0.002 \\
\hline Si & - & 0.06 & 0.05 & - \\
\hline $\mathbf{W}$ & - & - & 1.0 & - \\
\hline $\mathbf{V}$ & - & - & 0.02 & - \\
\hline $\mathbf{Z r}$ & - & 0.07 & - & - \\
\hline
\end{tabular}

The volume fraction of $\gamma^{\prime}$ phase and temperature capability increases with $\mathrm{Al}$ and $\mathrm{Ti}$. However, total sum of $\mathrm{Al}$ and $\mathrm{Ti}$ contents above $4 \mathrm{wt}$. \% are seldom seen in structural parts such as the one shown in Figure 1 due to the fact that they are very difficult to weld from a SAC perspective which is the main topic of the present paper.

\section{Weldability}

Weldability is an arbitrary expression for many reasons but nevertheless frequently used to explain different aspects in the welding of different alloys. It is very important to define what is meant by this expression to avoid confusion. One definition commonly used, not at least by the present author, is how susceptible a material is to cracking during welding. This definition usually incorporate cracks associated with different types of liquation during welding and they are called hot cracks. Warm cracking, on the other hand, more or less excludes liquation and takes place during the post weld heat treatment (PWHT). A third type of cracking is cold cracking which generally is associated with embrittling species like $\mathrm{H}$ or $\mathrm{S}$ during the service of the component $[8,9]$.

This paper focuses on hot and warm cracking which constitute the largest problem in the production of aerospace components. It should also be emphasized that the mechanical 
properties of welds is not included in the above definition but could still have a major impact on what is usually considered as the overall "weldability" of an alloy. Mechanical performance, balanced with processability, i.e. welding, is always a major concern in alloy development.

It can be stated that cracking is a serious issue (no matter what category) since it primarily at the end affect the engine life which is the reason why non destructive testing is always employed at different stages during the manufacturing as well as during the service life of aerospace structural components. There is a strong desire to avoid weld cracks since repair work can be reduced and the component life extended.

\section{Hot cracking}

Weld cracking theories originates back to research on hot tears during casting. The most wellknown are the "Strain theory of hot tears" [10] and the "Shrinkage-Brittleness theory" [11] which later were combined into Borland's combined theory known as the "Generalized theory" [12]. There are other theories as well [13-16] where the following material factors are believed to affect the susceptibility to hot cracking [9]:

1. The solidification temperature range.

2. The amount and distribution of liquid at the final stage of solidification.

3. The primary solidification mode.

4. The surface tension of the grain boundary liquid.

5. The grain structure.

Segregation obviously affects the above parameters and is usually defined by the widely used partitioning coefficient. It's for instance known that $\mathrm{S}, \mathrm{O}, \mathrm{B}, \mathrm{P}, \mathrm{C}, \mathrm{Ti}, \mathrm{N}, \mathrm{H}$ and $\mathrm{Nb}$ partitions into the inter-dendritic regions during solidification and as a consequence suppress the melting point. The presence of these elements is also important in the eutectic phase reactions both during heating and cooling [17]. As a result of low melting impurities or constituents, so called wetting films are created which significantly reduces grain boundary ductility [18]. For instance, it is known that $\mathrm{Nb}$, which is present in Alloy 718 promotes the formation of $\mathrm{NbC}$ and Laves eutectic products. The latter is supposed to be more detrimental since it solidifies at a lower temperature and thus extends the solidification interval [19-27]. The chemical composition in general and the presence of $\mathrm{Nb}$ and $\mathrm{C}$ in particular is important in this context $[8,19,28]$. However, it has been concluded that a eutectic liquid is not always detrimental for the hot cracking since in some cases it has been shown to heal cracks by backfilling [29-32]. Some researchers have monitored the grain structure of the weld deposit through variation of the weld process parameters in order to optimize the weldability. It is generally concluded that an equiaxed grain structure in the weld deposit is less susceptible compared to a columnar structure [9]. This is due to better accommodation of strain, liquid feeding and lower concentration of impurity elements $[9,33]$.

In superalloys of the kind presented in this paper it has been seen that the liquation of grain boundaries determines how susceptible an alloy is to hot cracking [8]. The liquation can take place in different ways but is most often associated with melting point depressant elements like B [34-37] and S [38-39] and secondary phase constituents which, through a mechanism known 
as constitutional liquation, may form a liquid phase with the matrix phase, forming eutectic constituents as a result [34-37]. Another mechanism is known as segregation induced liquation which may take place during grain migration sweeping impurity elements along causing solute accumulation in these boundaries [9].

The pre-weld microstructure influences the material response due to the above liquation mechanisms. However, it is not uncommon to find contradicting results in literature on what material condition is the most favorable. It is generally believed that the softest possible solution heat treated condition together with a fine grain structure is preferable compared to the material in the aged and hard condition with a coarse microstructure $[8,44]$. This is attributed to the better ability of small grains to accommodate straining and to a lower concentration of impurity elements at the grain boundaries due to a larger grain surface area of material in the fine grain state compared with the same material in the coarse grain state [9].

Secondary phases present in Alloy 718 and their influence on liquation cracking has been shown to be attributed to the constitutional liquation of $\mathrm{NbC}$ in the wrought form and to $\mathrm{NbC}$ together with Laves in the cast form [45-46]. The presence of a phase known as the $\delta$ phase $\left(\mathrm{Ni}_{3} \mathrm{Nb}\right)$ has been claimed to improve the cracking resistance through a "solute blocking mechanism" [47] (reducing the amount of free $\mathrm{Nb}$ ) or by grain boundary pinning [48] while others have claimed that the $\delta$ phase will increase the susceptibility to liquation cracking by assisting liquation [4950]. This issue is still to be resolved. Grain boundary segregation of minor elements like B, P, C and S will most likely increase the HAZ liquation cracking in both Alloy 718 and Waspaloy [8, 51]. HAZ liquation in Waspaloy has been suggested to occur by the segregation of minor elements like B [52] and also through a "pipeline" diffusion of $\mathrm{Al}$ and Ti from the FZ to the HAZ [53] and by constitutional liquation of TiC phase [34]. Information on ATI 718Plus ${ }^{\circledR}$ is more limited. However, it seems likely that both large grain size [48] and high B and P levels in a modified ATI 718Plus ${ }^{\mathbb{B}}$ alloy have an impact on weld cracking [32]. The same study also indicated that cracking in Waspaloy was due to the extensive precipitation of inter- and intragranular $\gamma$ '. It has also been shown that ATI 718 Plus ${ }^{\circledR}$ and Alloy 718 behave strong similarities in terms of liquation, but differ significantly considering the precipitation hardening response [48].

\section{$\underline{\text { Warm cracking }}$}

Strain age cracking (SAC) is a type of cracking that occurs in the solid state due to hardening in the material. Cracking takes place when weld stresses are high at the same time as hardening occurs in precipitation hardening superalloys and in $\gamma^{\prime}$ hardening alloys in particular. SAC generally occurs during the post weld heat treatment (PWHT) and is consequently sometimes referred to as "PWHT cracking" or "Reheat cracking". An important feature in the context of what type of cracking takes place during welding is that SAC may actually also occur during welding, e.g. during multipass repair welding $[8,48]$. SAC is more or less only a problem for y' hardening superalloys and was one of the major reasons why Alloy 718 had such a success since there was a large demand for a high temperature capable alloy which was readily weldable. The reason is that Alloy 718 is more or less immune to SAC is due to its sluggish hardening response of $\gamma$ " phase.

The so called PWHT is carried out to restore strength of the fusion zone (FZ) as well as the heat affected zone (HAZ) through a full solution and hardening processing cycle that at the same time relieves stresses that are always introduced by the welding. This stress relief is unfortunately 
concomitant with uncontrolled hardening during the heating cycle of the heat treatment which imposes high strain on the grain boundaries. In addition, hardening of the alloy generally leads to a reduced overall ductility [54]. This loss of ductility may on its own lead to something known as ductility dip cracking (DDC), another type of cracking more commonly encountered in solid solution hardening alloys, where it is thus not related to precipitation hardening. The ductility drop is presumably associated with severe strain concentrations at grain boundary triple points due to grain boundary sliding. Research has indicated the beneficial effects of carbide precipitation (e.g. $\mathrm{M}_{23} \mathrm{C}_{6}$ and $\mathrm{MC}$ ) in resisting grain boundary sliding and decohesion at elevated temperatures. It is believed that precipitation of $\mathrm{MC}$ carbides beneficially restrict grain boundary migration, and hence creates tortuous grain boundaries by pinning [55].

Regarding SAC, other factors than those mentioned above may increase the susceptibility to cracking. A relation between $\mathrm{Al}$ and Ti was proposed by Prager and Shirra, who suggested that a strong influence on the precipitation characteristics of the $\gamma^{\prime}$ phase exists [56]. Basically, the higher the content of these hardening elements, the more susceptible the alloy will be since a higher volume fraction of the y' phase is present [2]. It has also been reported that carbide films at the grain boundaries together with partially liquated grain boundaries increase the susceptibility to cracking [57]. These material specific factors together with the stresses developed during the welding operation add to the severity of the cracking.

\section{$\underline{\text { Weldability Testing }}$}

There are many "weldability" testing methods where the term "weldability" often refers to the "inherent" resistance to cracking in a material during welding [8]. It should be noted that there is no testing method which can be used to uniquely forecast the cracking and/or service performance of welds. Each weldability testing method has its own specific character. The different techniques available can be divided into different categories; the representative tests, simulative tests and high temperature mechanical tests [58].

Another concern relates to the fact that none of these methods have been properly standardized and large variations in the actual setup of the testing are evident although the name of the test is the same. The lack of standardization in actual testing and interpretation of results have lead to misleading results in some cases [59].

\section{Discussion}

It is often difficult to separate what kinds of cracking - HAZ liquation cracking, solidification cracking or SAC - that have occurred in the manufacturing of aerospace components. All these cracking mechanisms may be active at one or several occasions during manufacturing. This can often lead to misunderstandings of the overall weldability of a specific alloy. In the manufacturing shop, Waspaloy is known by real welders (!) to be the worst alloy to weld in comparison with the other alloys of our interest. However, when performing Varestraint weldability testing it has been reported that Waspaloy actually possess a better "weldability" in comparison with e.g. Alloy 718 [60]. The reason or logic becomes understandable from a metallurgical perspective when comparing the secondary phases and segregation involved in these alloys. Waspaloy has a narrow solidification interval and less segregation in comparison [48]. When representative type of tests are carried out involving reheating through multi-pass repair welding or heat treatment, it will reflect the fast age hardening response in Waspaloy, and 
consequently induce SAC which make it less weldable in comparison with Alloy 718 [61]. This is in agreement with the practical experience of welders who often carry out repair work.

The discrepancy between the actual welding environment in the manufacturing shop and the results from the different single weldability testing methods emphasizes the importance to incorporate several tests and analyze the results in concert to cover the full picture of weldability. If properly done, weld cracking during the manufacturing and repair of damaged components may be minimized. A schematic view of this integrated process to assess weldability (cracking response) is presented in Figure 2.

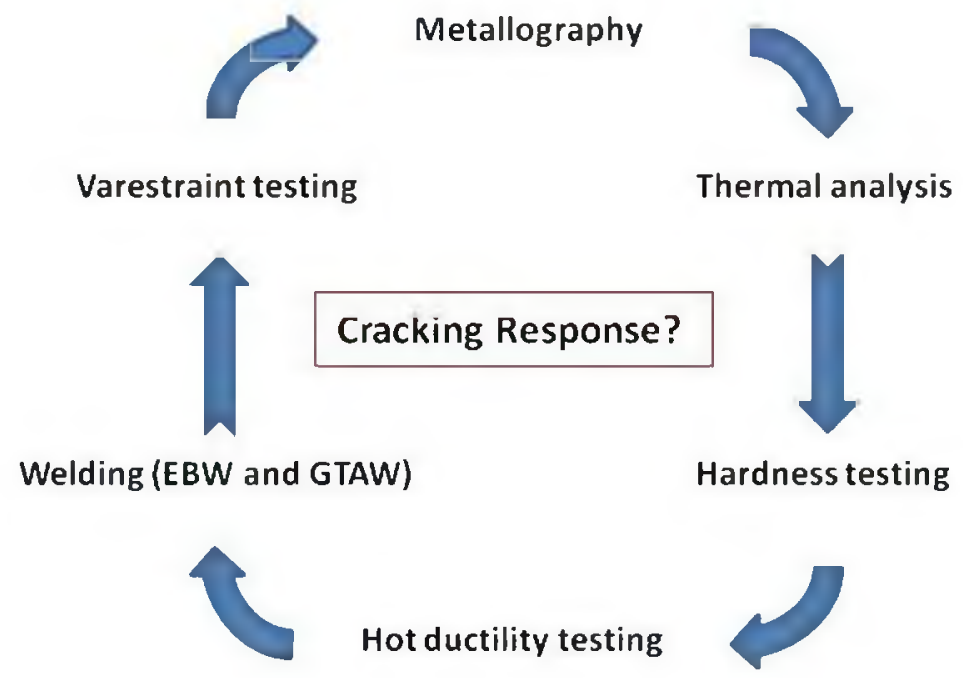

Figure 2. Proposed procedure to evaluate superalloy weldability.

The use of metallographic examinations of welds such as the one seen in Figure 3 often provides simple and good information in terms of what phases that constitute the actual material. In Figure 3 below, a hot crack in Alloy 718 is disclosed. This hot crack is surrounded by white mushy constituents known as the $\gamma$-Laves eutectic phase constituent which is one of the underlying factor for the susceptibility towards hot cracking in both Alloy 718 as well as ATI 718Plus ${ }^{\mathbb{B}}$.

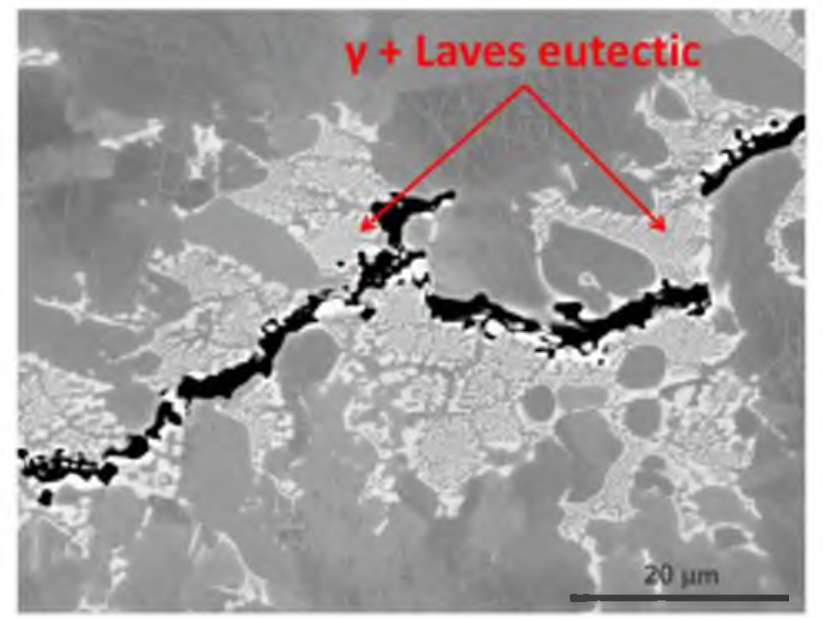

Figure 3. An example of a microstructure photo of a hot crack in Alloy 718 using scanning electron microscopy.

Weld and material microstructure information can be used for insight into the cracking mechanisms [62]. Thermal analysis aids in explaining possible phase reactions even though the 
heating and cooling rates are very slow compared to what is experienced during welding. In Figure 4, a differential scanning calorimetric thermograph of Alloy 718 is presented as an example on how the heating and cooling sequence in this material may look like. The information obtained through this type of testing can be coupled with the previous information gained by metallographic investigation to take one extra step in explaining underlying mechanisms related to weldability.



Figure 4. An example of a differential scanning calorimetric thermograph of Alloy 718 revealing various phase reactions both during heating (green curve) as well as during cooling (blue curve).

Hardness testing along with heat treatment or repair welding is a quick and easy way to rank and determine if the alloy is susceptible to SAC [61]. As can be seen in Figure 5, there is a significant hardness increase from the bottom layer weld deposits as compared to the top layers in the weld repaired groove of Waspaloy in this case. Furthermore, most of the cracks were found in the bottom layer weld deposits which suggests SAC to be of prime concern.

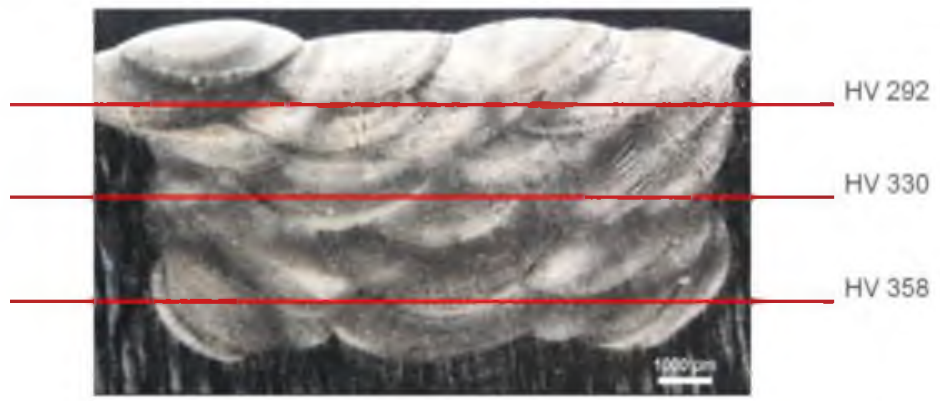

Figure 5. Hardness testing of a Waspaloy weld repaired groove reveals significant hardening response at a repair of this kind.

The well known Gleeble testing is normally used to determine the hot ductility which is invaluable to gain information about how phase reactions (e.g. liquation) during fast heating and cooling influence the ductility $[48,63]$. However, it can also be used to assess the susceptibility toward SAC. There has been several attempts to do this and most testing approaches are linked to the ductility response as it depends on the kinetics of the $\gamma^{\prime}$ phase. A proposed suggestion is shown in Figure 6a and $\mathbf{b}$ below. The first thing that applies to both $6 \mathbf{a}$ and $6 \mathbf{b}$ is that they include a simulated HAZ thermal cycle where after the second cycle differ in between $6 \mathbf{a}$ and $6 \mathbf{b}$. 
The simulated HAZ thermal cycle is very important to incorporate since it liquates the grain boundaries and will affect the upfront ductility behavior in the second cycle. The testing approach in Figure 6a is more suitable for high volume fraction $\gamma^{\prime}$ hardening alloys which has a significantly fast hardening response as well as a large negative mismatch in between the hardening phase and the matrix, a prerequisite for SAC. So, the second cycle in $6 \mathbf{a}$ involves fast heating to different age temperatures, followed by a certain pre strain and fixed yoke positioning in the Gleeble system until fracture occurs. The longer time it takes to fracture, the less susceptible to SAC. The approach in $6 \mathbf{b}$ is more suitable for low or medium $\gamma$ ' hardening alloys such as ATI 718 Plus ${ }^{\mathbb{B}}$, Waspaloy or Haynes ${ }^{(B)} 282^{\mathbb{B}}$. These alloys will most probably not go to fracture in using the first approach, they will only relax. However, by a slow heating rate $(6 \mathbf{b})$, similar to a PWHT, as well as slowly pulling a sample to fracture at different age temperature it will be possible to disclose the ductility behavior as influenced by the mismatch in between the $\gamma$ and $\gamma^{\prime}$ phases. A lower ductility and stress required for fracture will serve as a measure for susceptibility towards SAC.

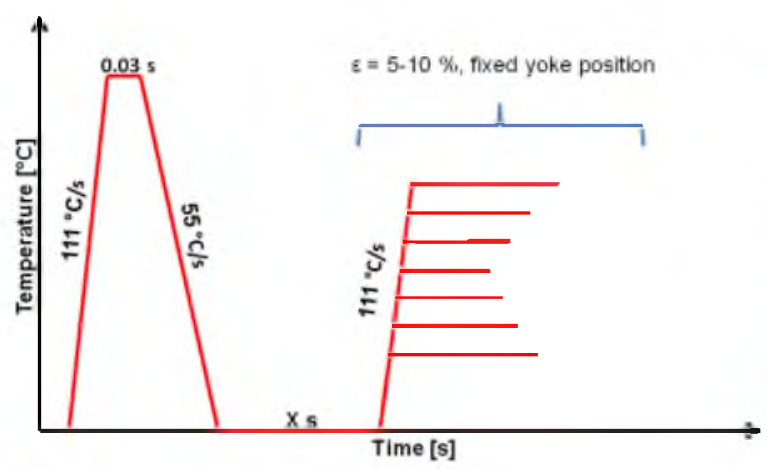

a

Figure $6 \mathbf{a}$ and $\mathbf{b}$. A proposed testing approach to assess the susceptibility towards SAC.

In Figure 7, a JMatPro a $\gamma-\gamma^{\prime}$ mismatch plot for Alloy 718 and Haynes ${ }^{\mathbb{B}} 282^{\mathbb{B}}$ can be seen. As pointed out earlier, Alloy 718 is more or less immune to SAC which can be explained by the mismatch in Figure $7 \mathbf{a}$ which does not reveal any negative mismatch at all compared to Haynes ${ }^{\mathbb{R}}$ $282^{\mathbb{B}}$ which does possess a negative mismatch and a presumed ductility dip at around $\sim 850^{\circ} \mathrm{C}$.

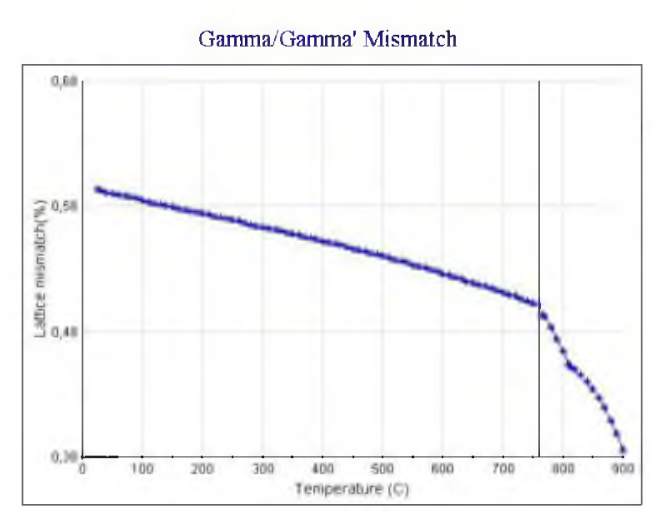

a

Figure 7. JMatPro modeling of the $\gamma-\gamma^{\prime}$ mismatch in Alloy 718 (7a) and Haynes ${ }^{\circledR} 282^{\circledR}$ (7b). 
One concern with the Gleeble testing is that results may only be valid for the high heat input weld processes such as submerged arc welding [9]. The significance of the Gleeble test results depends on the present liquation mechanism of specific alloys as well as on the pre-weld condition; e.g. grain size and phase constituents. This is also why it is suggested to evaluate different welding processes, such as electron beam welding and gas tungsten arc welding which provides very different heat input, in terms of how these processes may trigger liquation mechanisms. Last but not least is the Varestraint weldability testing method which is a suitable method to assess susceptibility towards hot cracking by exposing a sample to an external and augmented bending force on top of the weld shrinkage strain. This approach enables a route to rank different materials, evaluate heat treatments, welding parameters etc. A new Varestraint weldability testing machine was developed and built by the present author at GKN Aerospace Sweden a couple of years ago, (Figure 8), and is now integrated together with the above proposed procedure in assessing the overall weldability of precipitation hardening superalloys. The machine consists of three different units; a hydraulic unit (to the left) which provides the force to the 100 metric ton capability press (to the right) and is integrated with a welding robot. The welding method can be changed depending on what type of process is of interest.

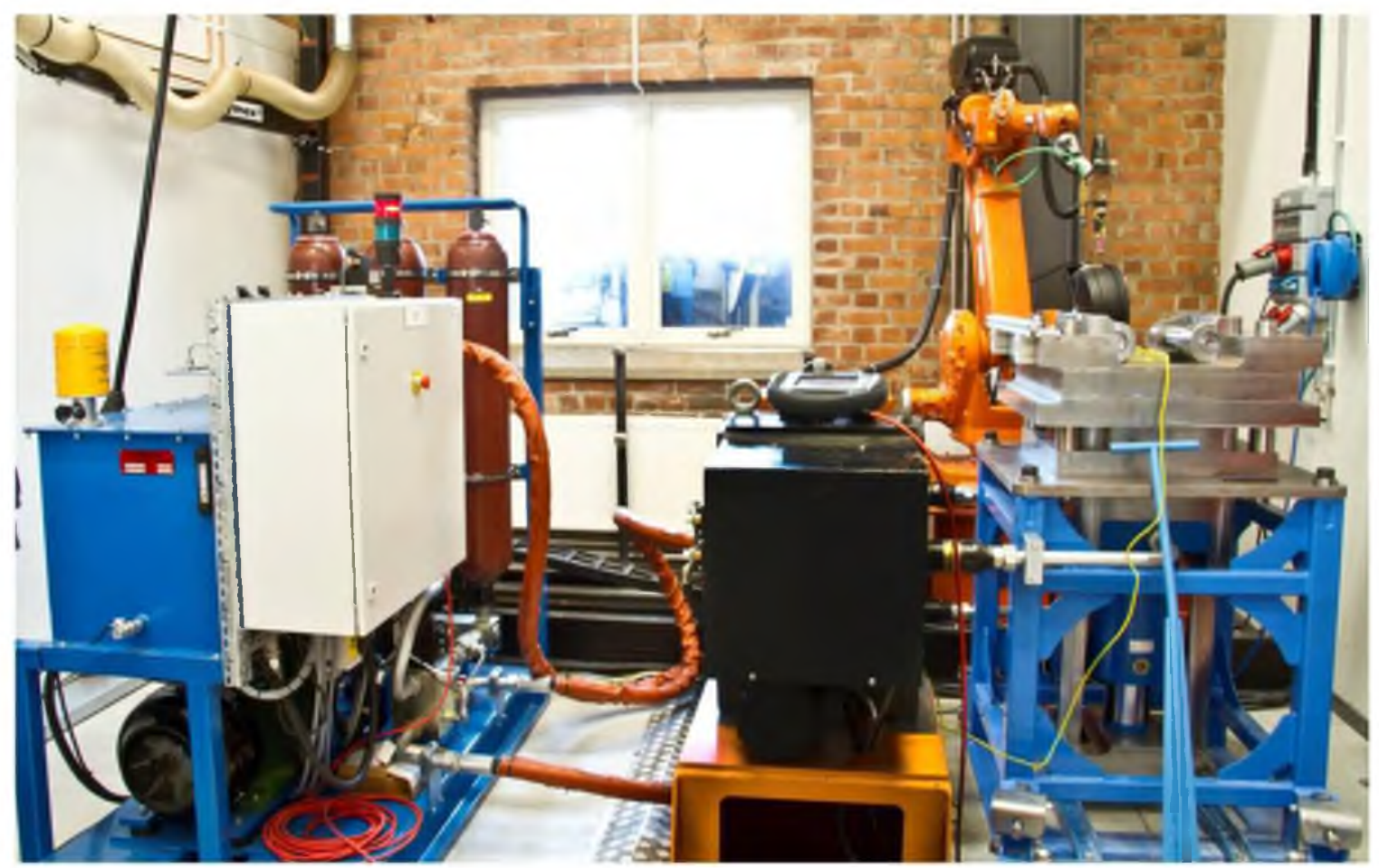

Figure 8. The newly developed Varestraint weldability testing method as designed and built at GKN Aerospace Sweden.

Testing methods like the Varestraint and Gleeble tests can furthermore be used to develop different crack criteria which can be used to predict either hot cracking and/or SAC. The important take away from this review and new suggestions is to understand the importance in that many different mechanisms play a role in the overall weldability of these alloys and should therefore be treated with care. It is highly recommended to use several methods like the proposed procedure in this paper when assessing the overall weldability to avoid unwanted surprises. 


\section{Conclusions}

A review of the weldability of precipitation hardening Ni-based superalloys has been made and an integrated evaluation procedure for the overall weldability as well as a testing approach for accessing the susceptibility to SAC of precipitation hardening Ni-based superalloys is proposed in this paper.

1. Different type of cracking and associated mechanisms may be active at the same time and may interact.

2. The weldability concept needs to be evaluated in relation to specific welding processes since the cracking mechanisms may vary between these processes.

3. A systematic integrated procedure is suggested to assess weldability in a consistent and cost effective way.

\section{Acknowledgements}

Professor Olanrewaju Ojo and Dr. Krutika Vishwakarma at University of Manitoba in Canada as well as Dr. Göran Sjöberg at GKN Aerospace Sweden are acknowledged for reviewing the paper.

\section{References}

1. R.C. Reed, 'The Superalloys: Fundamentals and Applications', Cambridge University Press, 2006.

2. C. T. Sims, N. S. Stoloff, and W. C. Hagel: 'Superalloys II', John Wiley \& Sons, 1987.

3. G. Sjöberg, J. Andersson, and A. Sjunnesson: Proceedings of International Society for Airbreathing Engines (ISABE), Montreal, Canada, September, 2009, n.1286.

4. Special Metals Corporation: 'INCONEL ${ }^{\mathbb{B}}$ Alloy 718 Product Brochure', Publication Number SMC-045, September, 2007.

5. Special Metals Corporation: 'Waspaloy Alloy Product Brochure', Publication Number SMC011 , September, 2004.

6. ATI ALLVAC: 'ATI 718 Plus ${ }^{\circledR}$ Alloy Product Brochure', Publication Number NI-417 VERSION 1, 2010.

7. Haynes International Inc.: 'HAYNES ${ }^{\circledR} 282^{\circledR}$ Alloy Product Brochure', Publication Number H-3173, 2008.

8. J. N. DuPont, J. C. Lippold, and S. D. Kiser: 'Welding Metallurgy and Weldability of Nickel-Base Alloys', John Wiley \& Sons Inc., USA, 2009.

9. S. Kou: 'Welding Metallurgy', $2^{\text {nd }}$ ed., John Wiley and Sons, 2003.

10. W. S. Pellini: 'Strain theory of hot tearing', Foundry, 80, 1952, p. 125.

11. W. I. Pumphrey, and P. H. Jennings: 'A Consideration of the Nature of Brittleness at Temperatures above the Solidus in Castings and Welds in Aluminum Alloys', J. Inst. Metals, 75, 1948, p. 235.

12. J. C. Borland: 'Generalized theory of super-solidus cracking in welds (and castings)', British Welding Journal, 7, 1960, pp. 508-512.

13. D. G. Eskin, and L. Katgerman: 'A quest for a new hot tearing criterion', Metallurgical transactions A, 38, 2007, pp. 1511-1519.

14. C. E. Cross: 'On the Origin of Weld Solidification cracking', Hot Cracking Phenomena in Welds, ed. T. Böllinghaus, and H. Herold, Springer-Verlag Berlin Heidelberg, 2005, pp. 318. 
15. C. E. Cross, and N. Coniglio: 'Weld Solidification Cracking: Critical Conditions for Crack Initiation and Growth', Hot Cracking Phenomena in Welds II, ed. T. Böllinghaus, H. Herold, C. E. Cross, and J. C. Lippold, Springer-Verlag Berlin Heidelberg, 2008, pp. 39-58.

16. K. A. Yushchenko, and V. S. Savchenko: 'Classification and Mechanisms of Cracking in Welding High-Alloy Steels and Nickel Alloys in Brittle Temperature Ranges', Hot Cracking Phenomena in Welds II, ed. T. Böllinghaus, H. Herold, C. E. Cross, and J. C. Lippold, Springer-Verlag Berlin Heidelberg, 2008, pp. 95-114.

17. H. Fredriksson, and U. Åkerlind: 'Materials Processing During Casting', John Wiley \& Sons, 2006.

18. K. Easterling: 'Introduction to the physical metallurgy of welding'. Butterworth-Heinemann, 1992.

19. M. J. Cieslak: 'The welding and solidification metallurgy of Alloy 625', Welding Journal, 70, 1991, pp. 49-56.

20. J. N. DuPont: 'Solidification of an Alloy 625 Weld Overlay', Metallurgical Transactions A, 27, 1996, pp. 3612-3620.

21. G. A. Knorovsky, M. J. Cieslak, T. J. Headley, A. D. Romig, and W. F. Hammetter: 'INCONEL 718: A solidification diagram', Metallurgical Transactions A, 20, 1989, pp. 2149-2158.

22. M. J. Cieslak, G. A. Knorovsky, T. J. Headley, and A. D. Roming: 'The use of New PHACOMP in understanding the solidification microstructure of nickel base alloy weld metal', Metallurgical Transactions A, 17, 1986, pp. 2107-2116.

23. M. J. Cieslak, T. J. Headley, G. A. Knorovsky, A. D. Romig Jr., and T. Kollie: 'A comparison of the solidification behavior on incoloy 909 and inconel 718', Metallurgical Transactions A, 21, 1990, pp. 479-488.

24. M. J. Cieslak, T. J. Headley, T. Kollie, and A. D. Romig: 'A melting and solidification study of Alloy 625', Metallurgical Transactions A, 19, 1988, pp. 2319-2331.

25. J. N. DuPont, J. R. Michael, and B. D. Newbury: 'Welding metallurgy of alloy HR-160' Welding Journal, 78, 1999, pp. 408-414.

26. S. W. Banovic, and J. N. DuPont: 'Dilution and microsegregation in dissimilar metal welds between super austenitic stainless steels and Ni base alloys', Science and Technology of Welding and Joining, 6, pp. 374-383.

27. J. N. DuPont, C. V. Robino, R. E. Mizia, and D. B. Williams: 'Physical and welding metallurgy of Gd-enriched austenitic alloys for spent nuclear fuel applications-part II: nickel base alloys', Welding Journal, 83, pp. 289-300.

28. J. N. DuPont, C. V. Robino, and A. R. Marde: 'Modeling solute redistribution and microstructural development in fusion welds of $\mathrm{Nb}$ bearing superalloys', Acta Metallurgica, 46, 1988, pp. 4781-4160.

29. C. Huang, and S. Kou: 'Liquation cracking in partial-penetration aluminum welds- effect of penetration oscillation and backfilling', Welding Journal, 82, 2003, pp. 184-194.

30. O.A. Idowu, O.A. Ojo, and M.C. Chaturvedi: 'Effect of heat input on heat affected zone cracking in laser welded ATI Allvac 718Plus superalloy', Materials Science and Engineering A, 454-455, 2007, pp. 389-397.

31. J. C. Lippold, J. Sowards, J Alexandrov, B. T. Murray, and A. J. Ramirez: 'Weld Solidification Cracking in Solid Solution Strengthened Ni-Base Filler Metals', Hot Cracking Phenomena in Welds II, ed. T. Böllinghaus, H. Herold, C. E. Cross, and J. C. Lippold, Springer-Verlag Berlin Heidelberg, 2008, pp.147 -170.

32. K. Vishwakarma: 'Microstructural Analysis of Weld Cracking in 718 Plus Superalloy', PhD thesis, University of Manitoba, Winnipeg, Canada, 2007. 
33. R. G. Thompson, J. J. Cassimus, D. E. Mayo, and J.R. Dobbs: 'The relationship between grain size and microfissuring in Alloy 718', Welding Journal, 64, 1985, pp. 91-96.

34. W. A. Owczarski, D. S. Duvall, and C. P. Sullivan: 'A model for heat affected zone cracking in nickel base superalloys', Welding Journal, 45, 1966, pp. 145-155.

35. R. Vincent: 'Precipitation around welds in the nickel-base superalloy Inconel 718', Acta Metallurgica, 33, 1985, pp. 1205-1216.

36. M. C. Chaturvedi, N. L. Richards, and A. Saranchuk, in 'Superalloys 718, 625, 706 and Various Derivatives', Ed. E. Loria, TMS, 1997, pp. 743-751.

37. W. Chen, M. C. Chaturvedi, and N. L. Richards: 'Effect of B Segregation at GBs on HAZ Cracking in Wrought Inconel 718', Metall. Mater. Trans. A., 32, 2001, pp. 931-939.

38. G. R Thompson, J.R. Dobbs, and D. E. Mayo: 'The effect of heat treatment on microfissuring in Alloy 718', Welding Journal, 65, 1986, pp. 299-304.

39. W. F. Savage, E. F. Nippes, and G. M. Goodwin: 'Effect of minor elements on hot-cracking tendencies of Inconel 600', Welding Journal, 56, 1977, pp. 245-253.

40. J. J. Pepe, and W. F. Savage: 'Effects of constitutional liquation in 18-Ni maraging steel weldments', Welding Journal, 46, 1967, pp. 411-422.

41. W. A. Owczarski, D. S. Duvall, and C. P. Sullivan: 'Further heat-affected zone studies in heat resistant nickel alloys', Welding Journal, 46, 1967, pp. 423-432.

42. B. Radhakrishnan, and R. G. Thompson: 'A phase diagram approach to study liquation cracking in alloy 718, Metallurgical Transactions A, 22, 1991, pp. 887-902.

43. H. R. Zhang, and O. A. Ojo: 'Non-equilibrium liquid phase dissolution of $\delta$ phase precipitates in a nickel-based superalloy', Philosophical Magazine Letters, 89, 2009, pp. 787794.

44. R. G. Thompson, J. J. Cassimus, D. E. Mayo, and J.R. Dobbs: 'The relationship between grain size and microfissuring in Alloy 718', Welding Journal, 64, 1985, pp. 91-96.

45. E. G. Thompson: 'Hot cracking studies of alloy 718 weld heat-affected zones', Welding Journal, 48, 1969, pp. 70-79.

46. W. A. Baeslack III, and D. E. Nelson: 'Morphology of Weld Heat-Affected Zone Liquation in cast alloy 718', Metallography, 19, 1986, pp. 371-379.

47. C. Boucher, D. Varela, M. Dadian, and H. Granjon: 'Hot Cracking and Recent Progress in the Weldability of the Nickel Alloys Inconel 718 and Waspaloy', Revue de Metallurgie, 73, 1976, pp. 817-831.

48. J. Andersson: 'Weldability of precipitation hardening superalloys - influence of microstructure', PhD thesis, Chalmers University of Technology, Gothenburg, Sweden, 2011.

49. M. Qian: 'An Investigation of The Repair Weldability of Waspaloy and Alloy 718', PhD thesis, The Ohio State University, Columbus, USA, 2002.

50. R. Vincent: 'Precipitation Around Welds in the Nickel-Base Superalloy Inconel 718', Acta Metallurgica, 33, 1985, pp. 1205-1216.

51. N. L. Richards, and M. C. Chaturvedi: 'Effect of minor elements on weldability of nickel base superalloys', International Materials Review, 45, 2000, pp. 109-129.

52. M. Qian, and J. C. Lippold: 'The effect of multiple PWHTs cycles on the weldability of Waspaloy', Welding Journal, 81, 2002, pp. 233-238.

53. Z. Li, S. L. Gobbi, and J. H. Loreau: 'Laser Welding of Waspaloy sheets for aero-engines', Journal of Materials Processing, 65, 1997, pp. 183-190.

54. W. A. Owczarski: 'Process and metallurgical factors in joining superalloys and other high service temperature materials', Physical Metallurgy of metal joining, Metallurgical Society of AIME, 1980, pp.166-189. 
55. A. J. Ramirez, and J. C. Lippold: 'High temperature cracking in nickel-base weld metal, Part 2-Insight into the mechanism', Materials Science and Engineering A, 380, 2004, pp. 245258.

56. M. S. Prager, and C. S. Shira: 'Welding of Precipitation-hardening Nickel- base superalloys', Welding Researc Council Bulletin 128, 1968.

57. D. McKeown: 'Re-heat Cracking in High Nickel Alloy Heat-Affected Zone', Welding Journal, 50, 1971, pp. 201-206.

58. W. Lin, J. C. Lippold, and W. A. Baeslack: 'Analysis of weldability testing techniques for HAZ liquation cracking', Advacements in synthesis and processes, Toronto, Canada, 1992, p. M464.

59. T. Finton, and J. C. Lippold: 'Comparison of Weld Hot Cracking Tests - Summary of an IIW Round Robin Study', EWI Report No. MR0205, 2002.

60. J. Andersson, G. Sjöberg, L. Viskari, A. Brederholm, H. Hänninen and C. S. Knee: 'Hot cracking of Allvac 718Plus, alloy 718 and Waspaloy at varestraint testing', Proc. 47th Conf. Metallurgists (COM), (ed. M. Elboujdaini), 401-413; 2008, Winnipeg, Metallurgical Society of CIM.

61. J. Andersson and G. Sjöberg: 'Repair Welding of Wrought Superalloys', Science and Technology of Welding and Joining, 2012, 17 (1), 49-59.

62. L. Karlsson, E. L. Bergquist, S. Rigdal, and N. Thalberg: 'Evaluating Hot Cracking Susceptibility of Ni-Base SAW Consumables for Welding of 9\% Ni Steel', Hot Cracking Phenomena in Welds II, ed. T. Böllinghaus, H. Herold, C. E. Cross, and J. C. Lippold, Springer-Verlag Berlin Heidelberg, 2008, pp. 329-347.

63. J. C. M. Farrar: 'Hot Cracking Tests - The Route to International Standardization', Hot Cracking Phenomena in Welds, ed. T. Böllinghaus, and H. Herold, Springer-Verlag Berlin Heidelberg, 2005, pp. 291-304. 